\title{
Pre- and post-operative effects of statin on experimentally induced kidney chronic disease in Wistar rats
}

\author{
Fernando Meyer1*, Renato W Bach $^{1}$, Flavio Lobo Heldwein ${ }^{2}$ and MarcosTobias-Machado ${ }^{3}$ \\ ${ }^{1}$ Department of Urology and Master Program on Surgery, Catholic University of Parana (PUC/PR), Brazil \\ ${ }^{2}$ Department of Urology, Federal University of Santa Catarina, Brazil \\ ${ }^{3}$ Department of Urology, Faculdade de Medicina do ABC, São Paulo, Brazil
}

\begin{abstract}
Background: Statins are selective competitive inhibitors to Hydroxymethylglutaryl-CoA reductase, an enzyme that catalyzes the initial phase of cholesterol biosynthesis. Statins have hypolipemiant action and pleiotropic effects that may include nephroprotection. The aim of the present study is to analyze pre- and postoperative effects of statin on experimentally induced kidney chronic disease (KCD) in rats.

Method: Forty Wistar male rats were pre-operatively randomized. To Group 1 ( $\mathrm{n}=15)$, statin was orally administered for ten days pre-operatively, and for fifteen days after 5/6 nephrectomy. Rats of Group $2(n=15)$ just received statin post-operatively. Rats of Group 3 (sham, n=10) were just submitted to surgery. Urine and blood samples were collected to analyze serum urea, serum creatinine and proteinuria at three different moments of the experiment. Rats that survived after an observational period of thirty days ( $n=34)$ were submitted to ex-vivo excision of the remnant kidneys. Histopathologic analysis was performed by using three stains (hematoxilineeosine, Gomori tricromium and periodic-acid Shiffer) and four standard indexes (glomerulosclerosis, mesangiolysis, tubulointerstitial and vascular damage indexes).

Results: Statin treated groups presented lower means of urea in postoperative period. Group 2 had the lesser urea means. Statin induced proteinuria in healthy rats prior to nephrectomy. Proteinuria decreased after ten days after surgery in both statin treated groups. Group 2 showed lower mesangiolysis and tubulointerstitial damage scores when compared to other groups.
\end{abstract}

Conclusion: Use of statin slowed KCD progression in this animal experimentation model.

\section{Introduction}

Statins are selective competitive inhibitors to Hydroxymethylglutaryl-CoA reductase, an enzyme that catalyzes the initial phase of cholesterol biosynthesis [1,2]. They have powerful hypolipemic action but also present pleiotropic effects that may include nephroprotection [2].

Statins improve morphology and function on KCD by interfering in vascular complacency, endothelial function, nitrous oxide metabolism and proteinuria [1,3-5]. Several studies [2,6-14] were developed in order to analyze the use of statins on inflammation and fibrosis scenario on cellular and animal models. Some of them have demonstrated that statins diminished renal fibrosis on KCD $[10,11,13,14]$. Hartner, et al. described statin effects on mortality, proteinuria, glomerulosclerosis, macrophage infiltration, podocytes damage and glomerular ostheopœtin expression, but no effects on inflammation and cellular interstitial proliferation [15].

Wide use of statins in hypercholesterolemic patients has suggested that those drugs reduce cardiovascular risk in KCD patients and several clinical trials [16-23]. (HPS [16], CARE [17], PREVEND IT [18], D4 Study [19], AURORA [20,21], ALERT [22], SHARP [23]) had been proposed to study that effect. Relative risk for cardiovascular events were reduced in mild to moderate KCD patients in HPS [16] and CARE [17] studies. Patiens undergoing dialysis may not have their cardiovascular risk reduced by using of statin, as shown by $4 \mathrm{D}$ [19] and AURORA $[20,21]$ studies, although other trials $[22,24]$ including SHARP study [23], the larger of them, suggested the contrary.
A systematic revision [5] and two metanalysis [4,25] suggested that statin use reduces proteinuria levels, although PREVED IT study [18] showed no beneficial impact of statins on albuminuria for initial stages of KCD.

Using statins for preventing KCD is a less studied issue. Patti, et al. [8] have described lower incidence of contrast induced nephropathy after percutaneous coronary procedures when statins were given preoperatively.

\section{Subjects and methods}

Fourty Wistar male rats (Rattus norvegicus albinus, Rodentia mammalian) were submitted to an experimental study using the remnant kidney model (5/6) nephrectomy). Their ages vary from 110 and 180 days, their weights vary from $200 \mathrm{~g}$ and $280 \mathrm{~g}$. The rats were kept at Central Vivarium of PUC/PR through observation period under standard conditions - temperature between $20^{\circ} \mathrm{C}$ and $24^{\circ} \mathrm{C}$, controlled lightning (12-hour day/night cycle: $8 \mathrm{am} / 8 \mathrm{pm}$ ) and air relative

${ }^{*}$ Correspondence to: Fernando Meyer, Department of Urology and Master Program on Surgery, Catholic University of Parana (PUC/PR), Brazil, Tel: 554130150303; E-mail: fmeyer@urocentro.com

Key words: hydroxymethylglutaryl-CoA reductase inhibitors, chronic renal insufficiency, nephrectomy, wistar rats

Received: July 05, 2020; Accepted: September 28, 2020; Published: October 01, 2020 
humidity between 50 and $60 \%$. Ad libitum water and standard feeding for species were offered, except within the twelve-hours preceding surgical procedure, when they did not take anything but potable water to drink.

This study was previously authorized by the Ethical Committee on Animal Experimentation of PUC/PR, where it is registered as number 572, and it followed strictly what Brazilian Law 1794 foresees.

The animals were pre-operatively randomized to receive orally administered statin for ten days pre-operatively, then fifteen days after $5 / 6$ nephrectomy (Group 1, $n=15$ ), to receive statin for fifteen days postoperatively (Group 2, $\mathrm{n}=15$ ) or surgery only (Group 3, sham, $\mathrm{n}=10$ ). All animals received statin $0.2 \mathrm{mg} / \mathrm{ml}$ (Cravo \& Canela Compounding Pharmacy, Curitiba, Brazil), $2 \mathrm{mg} / \mathrm{kg} /$ day given by orogastric feeding tube.

Urine and blood samples were collected to analyze serum urea, serum creatinine, and proteinuria at three different moments of the experiment: D0 (two days before surgery), D10 and D30 (respectively ten and thirty days after surgery). Group 1 had other samples collected before starting to receive preoperative statin (D0c). Serum urea and creatinine were analyzed by colorimetric method (Bionostic Laboratory, Curitiba, Brazil). Proteinuria levels were quantitatively assessed by specific kit (ChoiceLine10 Urinalysis', Roche, Mannheim, Germany).

Anesthesia was induced by intramuscular injection of ketamine 50 $\mathrm{mg} / \mathrm{kg}$ and xylazine $10 \mathrm{mg} / \mathrm{kg}$. After trichotomy and ventral abdominal antisepsis, the rats were placed in horizontal dorsal decubitus position. A right-side nephrectomy followed by bipolar left-sided partial nephrectomy through midline ventral incision was performed. Peroperatory care included postural maintenance of airway permeability, prevention of bleeding through rigorous hemostasis, prevention of hypothermia and using of peritoneal analgesics.

Rats that survived after an observational period of thirty days after surgery $(n=34)$ were submitted to ex-vivo excision of the remnant kidneys through similar incision. They were then sacrificed using ketamine $\left(\mathrm{DL}_{50}\right)$.

After that removal, kidneys were fixed with $10 \%$ formaldehyde solution, embedded in paraffin and cut into $2-\mathrm{mm}$ sections. Histopathologic analysis was performed using three stains -hematoxiline-eosine (HE), Gomori tricromium (GT) and periodicacid Shiffer (PAS) and four standard indexes.

Glomerulosclerosis Index (GSI) [26,27] quantified mesangial matrix accumulation and sclerosis of the glomerular tuft through a score of 0 to 4 . Mesangiolysis Score (MS) was used to analyze the presence of mesangiolysis, defined as mesangial matrix attenuation and/or mesangial cells degeneration [28] (Figure 1).

Subsamples of 100 glomeruli per animal were systematically studied through a semiquantitative score of 0 to 4 . Tubulointerstitial changes characterized as tubular atrophy and dilatation, interstitial inflammation and fibrosis, were assessed using a semi-quantitative scoring system of 0-5 (Tubulointerstitial Damage Index, TDS [29]), modified by the authors (Figure 2). The Vascular Damage Score [30] analyzed interlobular vessels and small arteries through a semiquantitative score of 0-4 (Table 1).

The results were expressed by means, medians, minimal and maximal values, and standard deviation. The Friedman test was used for comparing quantitative variables and percentual variations at three

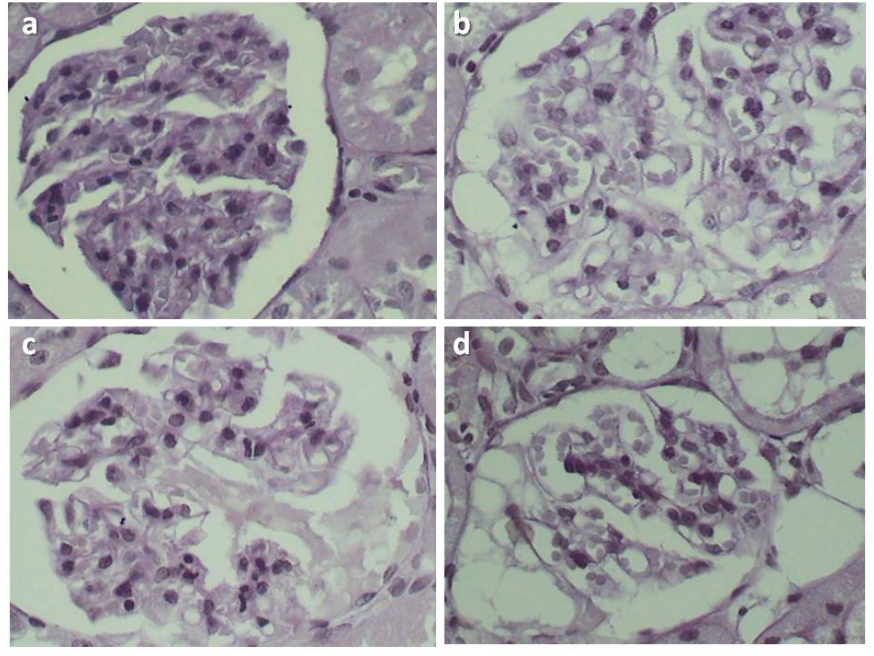

Figure 1. Mesangiolysis Score (MS). On periodic acid-Schiff stain one can observe: a) MS score 0 - no capillary changes; b) MS score 1 - capillary dilatation and/or $25 \%$ of capillary convolute; $\mathrm{c}$ and d) MS score 2 - capillary dilatation and/or $25 \%$ of convolute capillary or capillary aneurisms, or $50 \%$ of capillary convolute

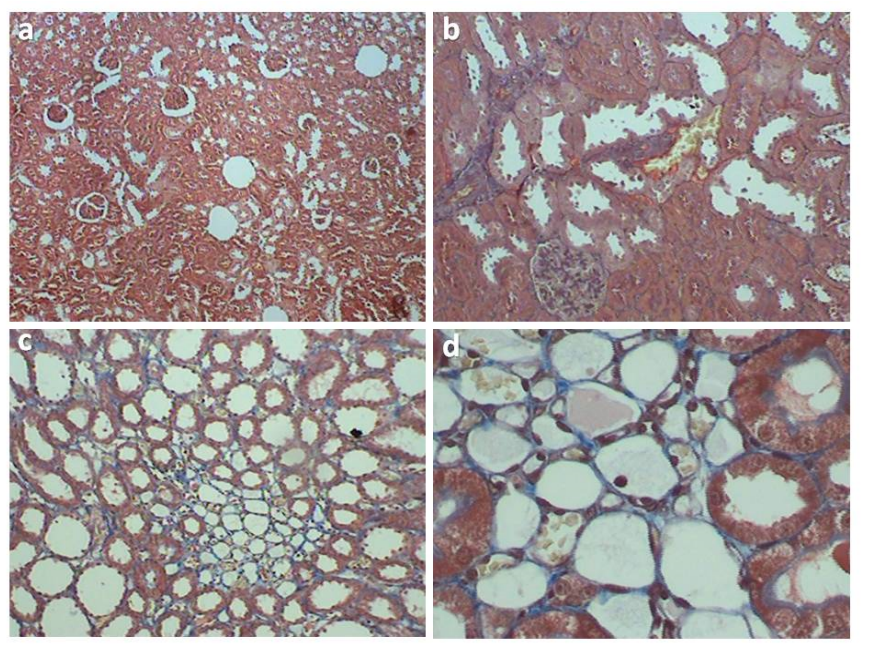

Figure 2. Tubulointerstitial Damage Index (TDI). On Gomori tricromium stain one can observe: $\mathrm{a}$ and b) TDI score 1 - normal tubulointerstitial structure; c and d) score 2 tubulointerstitial damage up to $10 \%$ of analyzed area

moments of evaluation. The Wilcoxon signed-rank test was used for comparing quantitative variables at two moments of evaluation when suitable. Kruskal-Wallis one-way analysis of variance was used for comparing percentual variation at two moments between the groups. Significance level was p-value lower than 0.05 . Fisher's exact test plus Bonferroni correction was used to evaluate histopathological scores when suitable.

\section{Results}

Thirty-four rats survived surgical procedure and observation period (Group 1, n=14, Group 2, n=12, Group 3, n=8). Overall mortality rate was $15 \%$, with $10 \%$ morbidity. Five rats died during the experiment. Inferior vena cava bleeding was observed in one case. Post-operative deaths occurred in 4 cases. Non-fatal peroperative bleeding was observed in 4 rats, accidental intestinal loop damage in one, incisional hernia in one. Loose adherences of liver, spleen, pancreas and intestine to kidney poles were common at reoperation procedures. 
Table 1. Histopathologic standard indexes

\begin{tabular}{|c|c|c|c|c|}
\hline Score & Glomerulosclerosis index & Mesangiolysis score & Tubulointerstitial damage index & Vascular damage score \\
\hline 0 & Normal glomerulus & No changes of capillaries & Normal tubulointerstitial structure & $\begin{array}{l}\text { No thickening of vascular } \\
\text { wall }\end{array}$ \\
\hline 1 & $\begin{array}{l}\text { Mesangial expansion or sclerosis up to } 25 \% \text { of } \\
\text { the glomerular tuft }\end{array}$ & $\begin{array}{l}\text { Capillary dilatation and/or } 25 \% \text { of capillary } \\
\text { convolute }\end{array}$ & $\begin{array}{l}\text { Tubulointerstitial damage up to } 10 \% \text { of } \\
\text { analyzed area* }\end{array}$ & $\begin{array}{l}\text { Mild thickening of vascular } \\
\text { wall }\end{array}$ \\
\hline 2 & Sclerosis of 25 to $50 \%$ & $\begin{array}{l}\text { Capillary dilatation and } / \text { or } 25 \% \text { of convolute } \\
\text { capillary or capillary aneurisms, or } 50 \% \text { of } \\
\text { capillary convolute }\end{array}$ & $\begin{array}{l}\text { Tubulointerstitial damage up to } 25 \% \text { of } \\
\text { analyzed area }\end{array}$ & $\begin{array}{l}\text { Moderate thickening of } \\
\text { vascular wall }\end{array}$ \\
\hline 3 & $\begin{array}{l}\text { Sclerosis of } 50 \text { to } 75 \% \text { and/or segmental } \\
\text { extracapillary fibrosis or proliferation }\end{array}$ & $\begin{array}{l}\text { Capillary aneurysms comprising } 50-75 \% \text { of } \\
\text { the capillary convolute }\end{array}$ & $\begin{array}{l}\text { Tubulointerstitial damage } 25 \% \text { to } 50 \% \text { of } \\
\text { analyzed area }\end{array}$ & $\begin{array}{l}\text { Severe thickening of } \\
\text { vascular wall }\end{array}$ \\
\hline 4 & $\begin{array}{l}\text { Global sclerosis, } 75 \% \text { of global extracapillary } \\
\text { fibrosis or complete collapse of the glomerular tuft }\end{array}$ & $\begin{array}{l}\text { Capillary aneurysms comprising } 75 \% \text { of the } \\
\text { capillary convolute }\end{array}$ & $\begin{array}{l}\text { Tubulointerstitial damage affecting } 50 \% \text { to } \\
75 \% \text { of analyzed area }\end{array}$ & $\begin{array}{l}\text { Fibrinoid necrosis of the } \\
\text { vascular wall }\end{array}$ \\
\hline 5 & 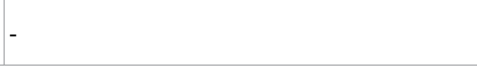 & - & $\begin{array}{l}\text { Tubulointerstitial damage in almost the } \\
\text { entire area }\end{array}$ & - \\
\hline
\end{tabular}

"Veniant, et al. described a score from 0 to 4 . The authors decided together with the pathologist to include one more rank between scores 0 and 1 (score 1 in the present study), in order to refine analysis of the tubulointerstitial area.

Table 2. Results of urea $(\mathrm{mg} / \mathrm{dl})$, creatinine $(\mathrm{mg} / \mathrm{dl})$ and proteinuria $(\mathrm{mg} / \mathrm{dl})$

\begin{tabular}{|c|c|c|c|c|c|c|c|c|}
\hline Group & $\mathbf{n}$ & Urea & & & & & Proteinuria & \\
\hline \multirow{5}{*}{1} & \multirow{5}{*}{14} & Moment & Mean" & $\mathrm{p}$ value & Mean $^{* *}$ & $\mathrm{p}$ value & Mean ${ }^{* * *}$ & $\mathrm{p}$ value \\
\hline & & D0c & 38.6 & $0.245^{* * * * *}$ & 0.5 & $0.367^{* * * * *}$ & 52.9 & $0.008^{* * * * *}$ \\
\hline & & D0 & 41.7 & \multirow{3}{*}{0.001} & 0.6 & \multirow{3}{*}{0.001} & 265.7 & \multirow{3}{*}{0.010} \\
\hline & & D10 & 67.2 & & 1.0 & & 216.4 & \\
\hline & & D30 & 78.7 & & 1.0 & & 136.4 & \\
\hline \multirow{3}{*}{2} & \multirow{3}{*}{12} & D0 & 37.5 & \multirow{3}{*}{0.001} & 0.5 & \multirow{3}{*}{0.001} & 105.0 & \multirow{3}{*}{0.002} \\
\hline & & D10 & 70.2 & & 0.8 & & 301.3 & \\
\hline & & D30 & 65.7 & & 0.9 & & 85.0 & \\
\hline \multirow{3}{*}{3} & \multirow{3}{*}{8} & D0 & 41.4 & \multirow{3}{*}{0.001} & 0.5 & \multirow{3}{*}{0.001} & 157.5 & \multirow{3}{*}{0.025} \\
\hline & & D10 & 93.1 & & 0.7 & & 557.5 & \\
\hline & & D30 & 101.3 & & 0.8 & & 650.0 & \\
\hline
\end{tabular}

Friedman's non-parametric test; $\mathrm{p}<0.05$

"Serum urea mean: Group 1: D10 $>$ D0, $\mathrm{p}<0.001 ; \mathrm{D} 30>\mathrm{D} 0, \mathrm{p}<0.001 ; \mathrm{D} 30>\mathrm{D} 10, \mathrm{p}=0.080$

Group 2: D10 $>$ D0, $<<0.001$; D30 $>$ D0, $<<0.001 ; \mathrm{D} 30>\mathrm{D} 10, \mathrm{p}=0.218$

Group 3: D10 $>$ D0, $<<0.001 ; \mathrm{D} 30>\mathrm{D} 0, \mathrm{p}<0.001 ; \mathrm{D} 30>\mathrm{D} 10, \mathrm{p}=0.049$

${ }^{*}$ Serum creatinine mean: Group 1: D10 $>$ D0, $<<0.001 ; \mathrm{D} 30>\mathrm{D} 0, \mathrm{p}<0.001 ; \mathrm{D} 30=\mathrm{D} 10, \mathrm{p}=0.056$

Group 2: D10 $>$ D0, $<<0.001 ; \mathrm{D} 30>\mathrm{D} 0, \mathrm{p}<0.001 ; \mathrm{D} 30>\mathrm{D} 10, \mathrm{p}=0.070$

Group 3: D10 $>\mathrm{D} 0, \mathrm{p}=0.001 ; \mathrm{D} 30>\mathrm{D} 0, \mathrm{p}<0.001 ; \mathrm{D} 30>\mathrm{D} 10, \mathrm{p}=0.195$

${ }^{* * *}$ Proteinuria mean: Group 1: D10<D0, p=1.000; D30<D0, p=0.005; D30<D10, p=0.005

Group 2: D10 $>$ D0, $<<0.001$; D30 $<\mathrm{D} 0, \mathrm{p}=0.545 ; \mathrm{D} 30<\mathrm{D} 10, \mathrm{p}<0.001$

Group 3: D10 $>$ D0, $<<0.044$; D30 $>$ D0, p $<0.004 ;$ D30 $>$ D 10, p $=0.254$

${ }_{* * * *}^{*}$ The Wilcoxon signed-rank test was used for comparing quantitative variables at two moments of evaluation. Level of significance was p-value $<0.05$.

Increasing of serum urea levels was observed in all three groups (Table 2). Sham rats (Group 3) presented progressive increasing of urea, confirmed when comparing two samples at a time. Increasing of serum urea levels in the two statin treated groups was precocious and it was not confirmed when we compare D10 and D30 (Group 1, p=0,080; Group 2, $\mathrm{p}=0,218$ ). Percentual variation analysis presented smaller variations in Group 2 in relation to Group 1 and Group 3).

Serum levels of creatinine increased in all groups nevertheless there was no difference between the groups or increasing levels after D10 for all of them (Tables 2 and 3).

Another blood and urine sample was taken from rats of Group 1 , at the day they started to be given statin (pre-treatment sample or D0c). When comparing these samples to D0 samples, it was observed that serum levels of urea and creatinine were not affected by the drug, but proteinuria did, corresponding to a variation mean of $556.7 \%$ $(p=0,008)$. Proteinuria decreased postoperatively but increased again until D30, with no significant difference between samples from D0c/ D0 and samples from D30 (Tables 2 and 3).

Group 2 presented precocious increasing of proteinuria, followed by decreasing until the end of the experiment. D0 and D30 levels were equal in this group. Both treated groups showed smaller levels of proteinuria in relation to Group 3 (Tables 2 and 3).

Glomerulosclerosis and vascular lesions were not observed in any group. Mesangiolysis was more evident in Group 3 rats. Smaller MSI scores were found in Group 2 when comparing to Groups 1 and 3 $(\mathrm{p}<0,001$ for both). TDS scores were smaller in Group 2, despite equal results in Groups 1 and 3 do not support statistical analysis (Table 4).

Other histopathologic findings included intraparenchimatous abscesses ( $n=9$, exclusively in treated groups), interstitial infiltrate $(n=3$, Groups 1 and 3$)$ and intratubular dystrophic micro calcification (Group 1, $\mathrm{n}=5$ ). Leukocytes were observed in one's rat urine sample (Group 1).

\section{Discussion and Conclusion}

Wide using of statin in the few last decades allowed researchers to observe many of its pleiotropic effects and to foresee its various uses in treating a range of diseases - linked or not to lipid metabolism. Many studies pointing to a role of statin in inflammation/fibrosis scenario [2,6-14], nephroprotection evidences $[10,11,13,14]$ and diminished cardiovascular risks in KCD patients in animal models [31] and 
Table 3. Percentual variation at two moments between the groups

\begin{tabular}{|c|c|c|c|c|c|c|c|c|}
\hline Variable & Group & $\mathrm{n}$ & Urea $^{*}$ & p-value & Creatinine & p-value & Proteinuria $^{* *}$ & p-value \\
\hline \multirow{3}{*}{ D0-D10 } & 1 & 14 & $70.2 \%$ & \multirow{3}{*}{0.056} & $134.5 \%$ & \multirow{3}{*}{0.491} & $150.5 \%$ & \multirow{3}{*}{0.113} \\
\hline & 2 & 12 & $93.3 \%$ & & $74.9 \%$ & & $414.3 \%$ & \\
\hline & 3 & 8 & $127.8 \%$ & & $47.0 \%$ & & $2908.1 \%$ & \\
\hline \multirow{3}{*}{ D30-D10 } & 1 & 14 & $21.2 \%$ & \multirow{3}{*}{0.005} & $-5.8 \%$ & \multirow{3}{*}{0.082} & $-31.5 \%$ & \multirow{3}{*}{0.009} \\
\hline & 2 & 12 & $-5.2 \%$ & & $23.3 \%$ & & $-59.3 \%$ & \\
\hline & 3 & 8 & $11.4 \%$ & & $7.8 \%$ & & $270.4 \%$ & \\
\hline \multirow{3}{*}{ D30-D0 } & 1 & 14 & $98.2 \%$ & \multirow{3}{*}{0.052} & $123.7 \%$ & \multirow{3}{*}{0.260} & $180.8 \%$ & \multirow{3}{*}{0.003} \\
\hline & 2 & 12 & $79.4 \%$ & & $95.7 \%$ & & $23.1 \%$ & \\
\hline & 3 & 8 & $151.9 \%$ & & $54.2 \%$ & & $2703.2 \%$ & \\
\hline
\end{tabular}

Friedman's non-parametric test; $\mathrm{p}<0.05$

"Serum urea percentual variation:

D30 - D10: Group 1 x Group 2 p=0.001; Group 1 x Group 3 p=0.299; Group 2 x Group 3 p=0.035

** Proteinuria percentual variation:

D30 - D10: Group 1 x Group 2 p=0.629; Group 1 x Group 3 p=0.006; Group 2 x Group 3

$\mathrm{p}=0.002$

D30 - D0: Group 1 x Group 2 p=0.306; Group 1 x Group 3 p=0.000; Group 2 x Group 3 p=0.05

${ }^{* * *}$ Kruskal-Wallis one-way analysis of variance was used for comparing percentual variation at two moments between the groups.

Table 4. Histopathological results

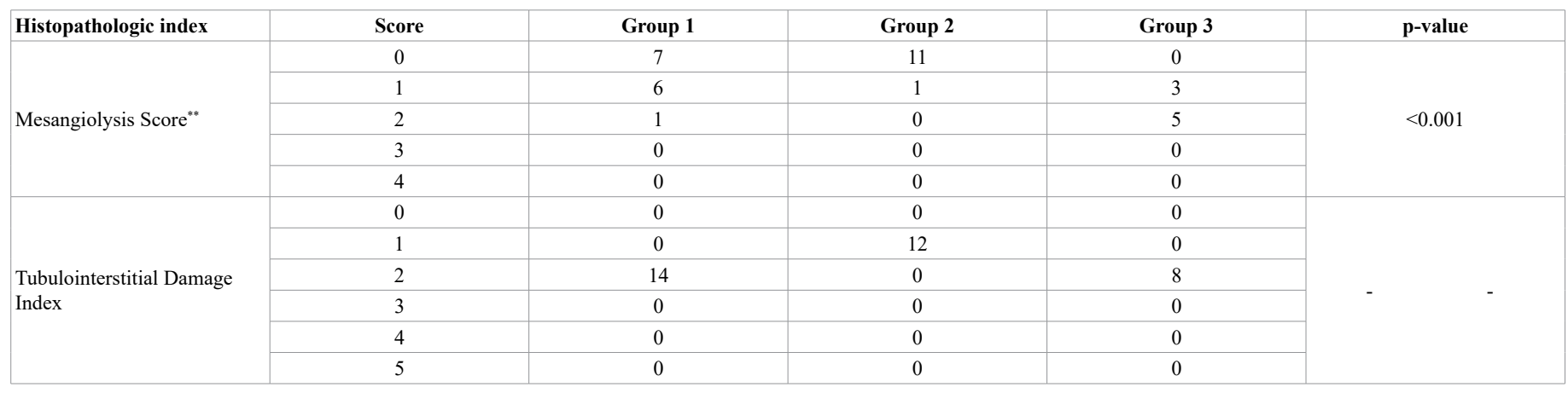

*Glomerulosclerosis and vascular damage were not observed

**Mesangiolysis Score: Group 1 versus Group 2, p=0.012; Group 1 versus Group 3, p $<0.001$; Group 2 versus Group 3, $<<0.001$.

****Given that Groups 1 and 3 have equal results, statistical analysis was not applied.

clinical trials [16-23] have stimulated us on studying that drug effects on experimentally induced $\mathrm{KCD}$ in rats.

Remnant kidney model was capable of induce KCD in sham rats (Group 3). Sample collection was easily achieved, but experience from our pilot study contraindicates it to be done at the very same day of 5/6 nephrectomy because of high mortality. Peripheric blood sampling has lesser hemodynamic impact on rats than cardiac blood sampling. Preoperative care should include hypothermia and bleeding prevention as rats and mice presents many systemic alterations as reflex of renal ablation [32-34].

Increasing of serum levels of urea and creatinine is inherent to the model and it was achieved in Group 3 (sham). Using of statin decreased serum urea levels in both treated groups (1 and 2), more evidently in the group that received statin both pre and post-operatively.

Serum levels of creatinine precociously increased in all three groups, with no difference between them, suggesting that statin use did not change creatinine levels in this study.

Previous papers $[1,3,4]$ showed that statins promote decreasing of proteinuria levels and they suggest three mechanisms for that: lesser glomerular protein filtration, blockage of filtered protein endocytosis and inhibition of inflammatory response. Douglas, et al. [4] studied fifteen clinical trials about statin in a metaanalysis, concluding that they are beneficial to patients with pathologic albuminuria. ALERT study [22], for instance, showed that fluvastatin did not have impact on proteinuria levels. Strippoli, et al. [25] showed that the reduction of proteinuria levels do not correspond to increasing in glomerular filtration rates, so the researchers question if proteinuria could have any clinical impact like bigger free-dialysis time.

Previous studies also state that almost all statins could promote proteinuria in patients that do not have KCD [4,5]. That effect is dosedependent and directly proportional to the power of the particular statin, and it is more common with rosuvastatin, a statin that is highly concentrated and excreted by the kidneys. Statin induced proteinuria has tubular pattern, mostly low molecular weight protein, and it represents a transient state of higher tubular reabsorption [5]. In our statin pre-treated group (Group 1), levels of proteinuria decreased precociously after surgery, to increase again until D30 although there was no difference between initial and final levels.

Absence of glomerulosclerosis and vascular lesions in our sample, including Group 3, may be explained by the short observation period. Some papers only achieved histopathologic alterations after greater periods of time as ten weeks [35-37]. Santos, et al. [34], however, when comparing various models of inducing KCD in Wistar rats, observed full remnant kidney recovery in only eight weeks. More studies are needed to correctly evaluate progression of KCD in Wistar rats and proper windows of observation. 
Mesangiolysis signs precedes glomerulosclerosis and were more evident in our sham group. The group that was treated post-operatively presented smaller scores of MSI when comparing to sham ( $\mathrm{p}=0,012)$, so as smaller TDS scores, despite of subjectiveness of the last analysis. Histopathologic findings demonstrate that Group 2 presented lower scores of glomerular and tubular damages. The association of statin and post-operatory kidney abscesses was not reported until the moment of publication of this article.

\section{References}

1. Zoja C, Corna D, Rottoli D, Cattaneo D, Zanchi C, et al. (2002) Effect of combining ACE inhibitor and statin in severe experimental nephropathy. Kidney Int 61: 16351645.

2. Vaziri ND (2010) Lipotoxicity and impaired high-density lipoprotein-mediated reverse cholesterol transport in chronic kidney disease. J Ren Nutr 20: S35-S43.

3. Danesh FR, Sadeghi MM, Amro N, Philips C, Zeng L, et al. (2002) Hydroxy3 methylglutaryl CoA reductase inhibitors prevent high glucose-induced proliferation of mesangial cells via modulation of Rho GTPasep21 signaling pathway: Implications for diabetic nephropathy. PNAS 99: 8301-8305.

4. Douglas K, O'Malley PG, Jackson JL (2006) Meta-analysis: the effect of statins on albuminuria. Ann Intern Med 145: 117-124.

5. Laurinavicius AG, Santos RD (2008) Dyslipidemia, statins and chronic renal insufficiency. Rev Bras Hypertens 15: 156-161.

6. Birnbaum Y, Lin Y, Ye Y, Merla R, Perez-Polo JR, et al. (2008) Pretreatment with highdose statin, but not low-dose statin, ezetimibe, or the combination of low-dose statin and ezetimibe, limits infarct size in the rat. J Cardiovasc Pharmacol Ther 13: 72-79.

7. Paraskevas KI, Liapis CD, Hamilton G, Mikhailidis DP (2008) Are statins an option in the management of abdominal aortic aneurysms? Vasc Endovascular Surg 42: 128-134.

8. Patti G, Nusca A, Chello M, Pasceri V, D'Ambrosio A, et al. (2008) Usefulness of statin pretreatment to prevent contrast-induced nephropathy and to improve long-term outcome in patients undergoing percutaneous coronary intervention. Am J Cardiol 101: 279-285.

9. Wiesbauer F, Heinze G, Mitterbauer C, Harnoncourt F, Höri WH, et al. (2008) Statin use is associated with prolonged survival of renal transplant recipients. J Am Soc Nephrol 19: 2211-2218.

10. Moriyama T, Kawada N, Nagatoya K, Takeji M, Horio M, et al. (2001) Fluvastatin suppresses oxidative stress and fibrosis in the interstitium of mouse kidneys with unilateral ureteral obstruction. Kidney Int 59: 2095-2103.

11. Vieira JM, Mantovani E, Rodrigues LT, Dellê H, Noronha IL, et al. (2005) Simvastatin attenuates renal inflammation, tubular transdifferentiation and interstitial fibrosis in rats with unilateral ureteral obstruction. Nephrol Dial Transplant 20: 1582-1591.

12. Michli E, Gulmi FA, Chou SY, Mooppan UM, Kim H (2007) Atorvastatin preserves renal function in chronic complete unilateral ureteral obstruction. J Urol 177: 781-785.

13. Chade AR, Zhu XY, Grande JP, Krier JD, Lerman A, et al. (2008) Simvastatin abates development of renal fibrosis in experimental renovascular disease. J Hypertens 26: 1651-1660.

14. Haydont V, Bourgier C, Pocard M, Lusinchi A, Aigueperse J, et al. (2007) Pravastatin Inhibits the Rho/CCN2/extracellular matrix cascade in human fibrosis explants and improves radiation-induced intestinal fibrosis in rats. Clin Cancer Res 13: 5331-5340.

15. Hartner A, Klanke B, Cordasic N, Amann K, Schmieder RE, et al. (2009) Statin treatment reduces glomerular inflammation and podocyte damage in rat deoxycorticosteroneacetate-salt hypertension. $J$ Hypertens 27: 376-385.

16. Heart Protection Study Collaborative Group (2002) MRC/BHF Heart Protection Study of cholesterol lowering with simvastatin in 20.536 high-risk individuals: a randomized placebo-controlled trial. Lancet 360: 7-22.

17. Tonelli M, Moyé L, Sacks FM, Cole T, Curhan GC (2003) Cholesterol and recurrent events trial I. Pravastatin for secondary prevention of cardiovascular events in persons with mild chronic renal insufficiency. Ann Intern Med 138: 98-104.
18. Asselbergs FW, Diercks GF, Hillege HL, van Boven AJ, Janssen WM, et al. (2004) Effects of fosinopril and pravastatin on cardiovascular events in subjects with microalbuminuria. Circulation 110: 809-816.

19. Wanner C, Krane V, März W, Olschewski M, Mann JF, et al. (2005) Atorvastatin in patients with type 2 diabetes mellitus undergoing haemodialysis. $N$ Engl J Med 353: 238-248.

20. Fellström BC, Jardine AG, Schmieder RE, Holdaas H, Bannister K, et al. (2009) Rosuvastatin and cardiovascular events in patients undergoing hemodialysis. $N$ Engl J Med 360: 1395-1407.

21. Holdaas H, Fellström B, Jardine AG, Holme I, Nyberg G, et al. (2003) Effect of fluvastatin on cardiac outcomes in renal transplant recipients: A multicentre, randomised, placebo-controlled trial. Lancet 361: 2024-2031.

22. Fellström B, Holdaas H, Jardine AG, Holme I, Nyberg G, et al. (2004) Effect of fluvastatin on renal end points in the Assessment of Lescol in Renal Transplant (ALERT) trial. Kidney Int 66: 1549-1555.

23. Baigent C, Landray MJ, Reith C, Emberson J, Wheeler DC, et al. (2011) The effects of lowering LDL cholesterol with simvastatin plus ezetimibe in patients with chronic kidney disease (Study of Heart and Renal Protection): A randomised placebo-controlled trial. Lancet 377: 2181-2192.

24. Wiesbauer F, Heinze G, Mitterbauer C, Harnoncourt F, Höri WH, et al. (2008) Statin use is associated with prolonged survival of renal transplant recipients. J Am Soc Nephrol 19: 2211-2218.

25. Strippoli GF, Navaneethan SD, Johnson DW, Perkovic V, Pellegrini F, et al. (2008) Effects of statins in patients with chronic renal disease: a meta-analysis and metaregression of randomized controlled trials. BMJ 336: 645-651.

26. Haas CS, Amann K, Schittny J, Blaser B, Muller U, et al. (2010) Glomerular and rena vascular structural changes in alpha8 integrin-deficient mice. J Am Soc Nephrol 14: 2288-2296.

27. Tsunenari I, Ohmura T, Seidler R, Chachin M, Hayashi T, et al. (2007) Renoprotective effects of telmisartan in the 5/6 nephrectomised rats. J Renin Angiotensin Aldosterone Syst 8: 93-100.

28. Dimmler A, Haas CS, Cho S, Hattler M, Forster C, et al. (2003) Laser capture microdissection and real-time PCR for analysis of glomerular endothelin- 1 gene expression in mesangiolysis of rat anti-Thy 1.1 and murine Habu Snake Venom glomerulonephritis. Diagn Mol Pathol 12: 108-117.

29. Veniant M, Heudes D, Clozel JP, Bruneval P, Ménard J (1994) Calcium blockade versus ACE inhibition in clipped and unclipped kidneys of $2 \mathrm{~K}-1 \mathrm{C}$ rats. Kidney Int $46: 421$ 429

30. Jung O, Jansen F, Mieth A, Barbosa-Sicard E, Pliquett RU, et al. (2006) Inhibition of the soluble epoxide hydrolase promotes albuminuria in mice with progressive renal disease. PLOS ONE 5: e11979.

31. Abe Y, Izumi T, Urabe A, Nagai M, Taniguchi I, et al. (2006) Pravastatin prevents myocardium from ischemia-induced fibrosis by protecting vascular endothelial cells exposed to oxidative stress. Cardiovasc Drugs Ther 20: 273-280.

32. Costa AFN, Pereira LPM, Ferreira ML, Silva PC (2009) Surgical model of chronic renal failure: Study in rabbits. Rev Col Bras Cir 36: 78-84.

33. Lutaif NA, Rocha EM, Veloso LA, Bento LM, Gontijo JA (2008) Renal contribution to thermolability in rats: role of renal nerves. Nephrol Dial Transplant 23: 3798-3805.

34. Santos LS, Chin EWK, Ioshii SO, Filho RT (2006) Surgical reduction of renal mass in rats: Morphologic and functional analysis on the remnant kidney. Acta Cir Bras 21: 252-257.

35. Fleck C, Appenroth D, Jonas P, Koch M, Kundt G, et al. (2006) Suitability of 5/6 nephrectomy $(5 / 6 \mathrm{NX})$ for the induction of interstitial renal fibrosis in rats--influence of sex, strain, and surgical procedure. Exp Toxicol Pathol 57: 195-205.

36. Erdely A, Wagner L, Muller V, Szabo A, Baylis C (2003) Protection of Wistar furth rats from chronic renal disease is associated with maintained renal nitric oxide synthase. $J$ Am Soc Nephrol 14: 2526-2533.

37. Lemos CC, Mandarim-de-Lacerda CA, Dorigo D, Coimbra TM, Bregman R (2005) Chronic renal failure in male and female rats. $J$ Nephrol 18: 368-373.

Copyright: $\odot 2020$ Meyer F. This is an open-access article distributed under the terms of the Creative Commons Attribution License, which permits unrestricted use, distribution, and reproduction in any medium, provided the original author and source are credited. 